\title{
Contribution to the Improvement of a Tomato Puree Dosing Machine
}

\author{
Edmond Claude Vodounnou, Guy Clarence Semassou*, Roger Ahouansou, \\ Priscille Yadonta
}

Abomey-Calavi Polytechnic, University of Abomey-Calavi, Cotonou, Benin

Email address:

clarence.semassou@gmail.com (G. C. Semassou)

${ }^{*}$ Corresponding author

\section{To cite this article:}

Edmond Claude Vodounnou, Guy Clarence Semassou, Roger Ahouansou, Priscille Yadonta. Contribution to the Improvement of a Tomato Puree Dosing Machine. Science Research. Vol. 9, No. 4, 2021, pp. 61-68. doi: 10.11648/j.sr.20210904.14

Received: July 21, 2021; Accepted: August 10, 2021; Published: August 18, 2021

\begin{abstract}
This article deals with the contribution to the improvement of a tomato puree dosing machine to facilitate the bottling of the puree during the tomato processing. Indeed, tomato processing is a way to reduce losses and extend its shelf life, while preserving its organoleptic characteristics as well as possible. However, we found that the production capacity is low compared to the demand because of the lack of financial means but also because of the laboriousness of the processing. Indeed, after reduction of the tomato in puree, its bottling is the longest and the most exhausting operation of the transformation process. To date, the filling of the jars is done with the manual filling machine developed by the PTAA researchers. But the uniformity of the filling is not respected, since it is done in an approximate way by the operator. To overcome this constraint, the issue of the study and design of a dosing machine for tomato puree was addressed. At the end of our study, we end up with a motorized dosing machine affordable for all small and medium-sized processing units. The results of the study will make it possible to remedy the manual filling, which will lead to increase the output of this transformation and thus indirectly to the valorization of the local varieties of tomato.
\end{abstract}

Keywords: Tomato, Puree, Dosing Machine, Organoleptic, Micronutrient

\section{Introduction}

In Benin, market gardening appears today as one of the main components of urban and peri-urban agriculture, following the example of small livestock (ruminants, poultry...) and is practiced in all regions of southern Benin [1]. Tomato (Lycopersicon esculentum Mill.), from the Solanaceae family, is one of the most important vegetable crops produced in Benin, both in terms of surface area $(45,000 \mathrm{ha})$ and production $(400,000$ tons $)$ in 2015 [2]. This production is very present in cropping systems [3] and in the population's diet. Nutritionally, tomatoes are a source of mineral salts, namely: $\mathrm{Ca}, \mathrm{K}, \mathrm{Mg}, \mathrm{Na}, \mathrm{Fe}$, and vitamins $\mathrm{A}$, $\mathrm{B} 6, \mathrm{C}$ and $\mathrm{E}$ [4], which contribute to the reduction of micronutrient deficiency in the consumer. Despite its importance, the tomato production chain remains unorganized in Benin. There is a long period of shortage from December to June and a short period of abundance from
August to November. During periods of overproduction, significant post-harvest losses are recorded because the tomato is a very fragile and perishable fruit due to its water content of over $85 \%$ [5]. The scarcity of supply during the lean season forces the import of fresh tomatoes from Nigeria and Burkina Faso, while more than $40 \%$ of national production is lost during the season of abundance due to the lack of effective means of conservation [6]. Since the industrial processing launched in the 1970s with the installation of a tomato paste factory in Natitingou (northwestern Benin) has failed, artisanal processing of tomatoes into puree is the most widespread form of processing/preservation to reduce these post-harvest losses [7]. Thus, previous work has attested to the technical feasibility of small-scale production of local tomato puree [8]. This transformation allows the crops to be preserved for several months or even several years (2 to 3 years) [9]. The difficulty of filling the bottles of puree is one of the constraints of this processing sector. This operation, quite 
time and labor consuming, is characterized by a low filling yield, a low production scale and risks of burns to operators due to the high temperature of the puree during filling. Studies were conducted for the development of a manual tomato puree filler by PTAA in 2008, for the design of a motorized filler by ODOU Magloire in 2012 and in 2016, a water filler in semi-automatic systems was carried out.

The present study proposes to contribute to the improvement of a filling machine by partially automating it and which is intended to equip the small and medium enterprises of transformation of tomato into puree in Benin and even in the sub-region to remedy the manual filling and to allow the uniform filling of the jars.

\section{Materials and Methods}

\subsection{Description of the Proposed Machine}

Figure 1 is a $3 \mathrm{D}$ and $2 \mathrm{D}$ design of the equipment on TopSolid software.

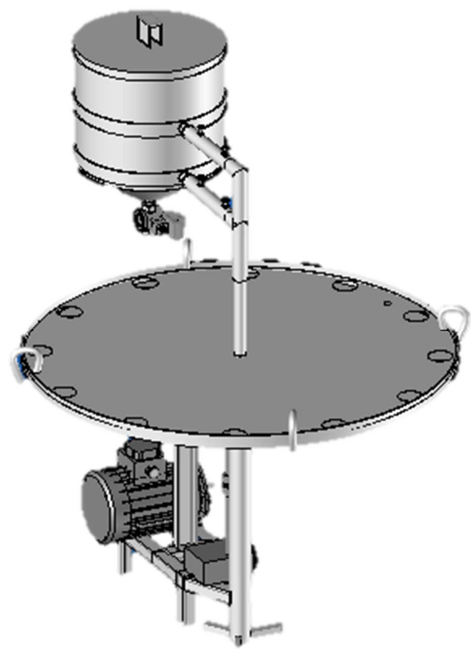

a

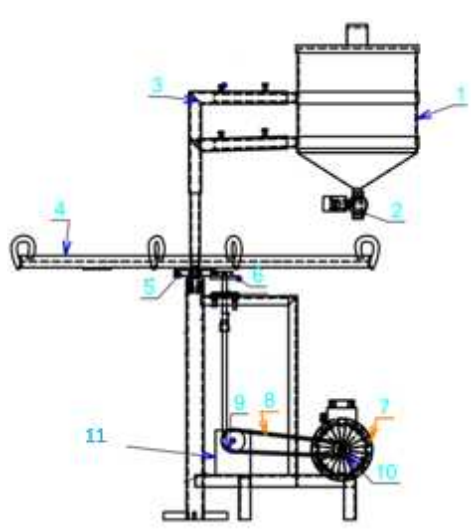

b

Figure 1. Representation of the dosing machine: (a) Block diagram of the dosing machine, (b) Plan drawing of the dosing machine.

(1): Tank; (2): Timed solenoid valve; (3): Upright; (4): Plate; (5): Maltese cross; (6): Crank pin; (7): Motor; (8): Belt; (9): Driven pulley; (10): Driving pulley; (11): Gearbox.
The main components of the machine are the timed solenoid valve, the Maltese cross mechanism, the tank, the plate, the post and the frame.

\subsubsection{Timed Solenoid Valve}

This allows the automatic opening and closing of the pump's discharge opening with defined setting times.

\subsubsection{Maltese Cross Mechanism}

The function of this mechanism is to transform the continuous rotation movement into an intermittent movement.

\subsubsection{The Tank}

It is used to store the mashed potato before packaging. It can contain a volume $\mathrm{V}=50 \mathrm{~L}$ of mashed potato. It is a welded construction obtained from a sheet of stainless steel 10/10 thick. A cone with a hole is made on its lower side to increase the speed of the mashed potato outlet. On the hole is realized a thread for the fixing of the electrovalve. The tank also has two clamps for fixing it to the upright.

\subsubsection{The Tray}

The tray is the element that supports the weight of the jars; it has holes that act as jar holders. It allows by its rotation movement around the shaft of the cross the positioning of the jars) the hole of the solenoid valve. A $\emptyset 20$ hole is also made on the tray to facilitate the evacuation of during its washing.

\subsubsection{Upright}

The upright is the component to which the clamps that support the tank are attached. It is provided with a threaded hole on its internal face which allows it to be fixed on the threaded part of the frame axis. It is of welded construction, made of 33/42 pipe.

\subsubsection{Frame}

This is the element that supports the tank and the motor. It is of welded construction. The shaft is made with a 50/60 pipe.

\subsection{Operating Principle}

Figure 2 is the kinematic representation of the dosing machine. It shows the operating principle of the equipment. When the motor (1) is switched on, the crosshead mechanism (7 and 8) drives the plate (9) in an intermittent rotation. With each turn of the cross (8), it makes an angle of $60^{\circ}$. When stopped, its position coincides with the position of a jar at the filling port of the solenoid valve. When the motor is started, a time delay starts at the same time. Thanks to the time delay, which is set to a defined time, the pump switches off automatically when the time is up. The operator then manually switches the pump on again and the cycle starts again. The regularity of the opening and closing time of the solenoid valve allows a uniform distribution of the product in the jars. 


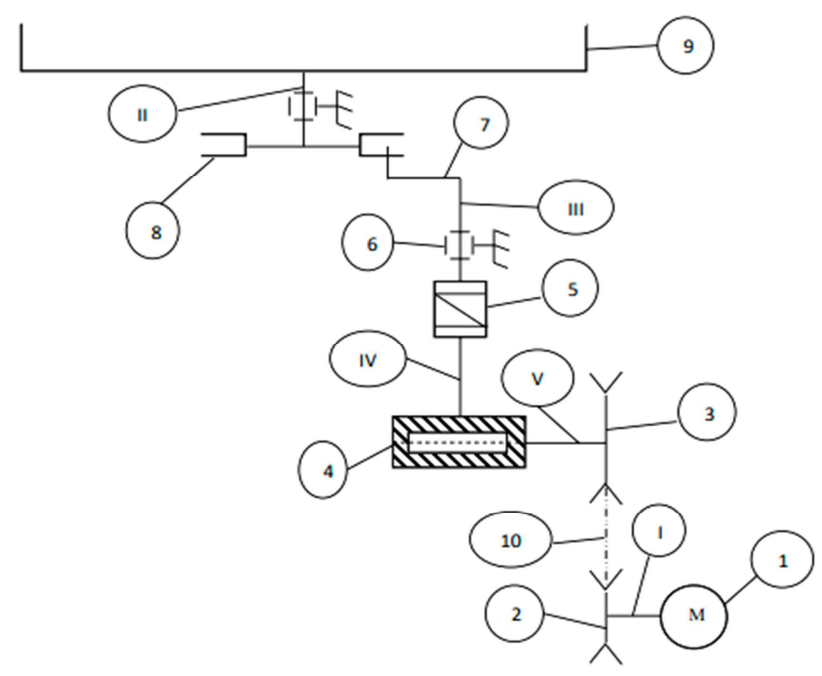

Figure 2. Kinematic diagram of the dosing machine.

1: Motor; 2: Driving pulley; 3: Driven pulley; 4: Gearbox; 5: Coupling; 6: Bearing; 7: Crank pin; 8: Maltese cross; 9: Plateau; 10: Belt

I: Motor shaft; II: Shaft I; III: Shaft II; IV: Shaft III; V: Shaft IV.

\subsection{Modeling}

This part is devoted to the identification of mathematical models relating to the various components of the dosing machine. These models reflect the physical phenomena that govern the functioning of the components.

The essential parameters of the dosing machine assembly are the dimensions of the Maltese cross mechanism, the speed of rotation of the Maltese cross, and the useful power.

\subsubsection{Dimensions of the Maltese Cross Mechanism}

The critical point of operation is the moment when the finger enters the groove. This imposes a relationship between the crank radius $R$, i.e. the distance between the center of the finger and the center of the driving wheel that supports it, and the center distance $E$, i.e. the distance between the center of the driving wheel and the center of the Maltese cross. For there to be no shock, the velocity vector must be in the axis of the groove [10]. We then have the following relationships between the center distance $\mathrm{E}$, the radius of the driving wheel $R_{1}$ and the radius of the driven wheel $R_{2}$ :

$$
\begin{aligned}
& R_{1}=E \sin \alpha(\mathrm{mm}) \\
& R_{2}=E \cos \alpha(\mathrm{mm})
\end{aligned}
$$

With $\alpha$ half the angle of rotation of the driven wheel per revolution of the driving wheel in radians.

\subsubsection{Speed of Rotation of the Maltese Cross}

The rotational speed of the Maltese cross will correspond to the inverse of the time of one revolution of the driving shaft in min.

$$
N=\frac{1}{T}
$$

where $\mathrm{N}$ is the speed of rotation in rpm and $\mathrm{T}$ is the time of one revolution of the drive shaft in min.

\subsubsection{Useful Power}

For the cross to rotate, it must support its own weight and that of the loads. The useful power is the product of the total moment of inertia, the angular velocity and the angular acceleration [11].

$$
P=I \times \omega_{0} \times \alpha_{0}(\mathrm{~W})
$$

\subsection{Drive System}

The drive train is composed of several types of transmissions that transform the engine power and determine the speed necessary for the proper operation of the equipment. It is characterized by two parameters: the total efficiency and the transmission ratio. The type of transmission used here is the pulley-belt transmission.

\subsubsection{Overall Efficiency}

The overall efficiency of the dosing machine is determined as follows [12]:

$$
\eta_{\text {global }}=\eta_{p}^{2} \times \eta_{c} \times \eta_{c r}
$$

With $\eta_{p}$ : efficiency per pair of bearings;

$\eta_{c r}$ : efficiency of the Maltese cross

$\eta_{c}$ : efficiency of the $\mathrm{V}$-belts.

\subsubsection{Transmission Ratio}

The transmission ratio is determined by:

$$
r=\frac{D^{\prime}}{D}=\frac{N_{M}}{N}
$$

With $D^{\prime}$ and $D$ respectively the diameters of the driven pulley and the small pulley (driving pulley) in $\mathrm{mm} ; N_{M}$ and $N$ respectively the rotation speeds of the driving pulley (motor) and the driven pulley in rpm.

\subsection{Motor}

It plays an important role in the design of the dosing machine. It is characterized by its power and speed. These parameters are decisive in the choice of the right motor for the dosing machine.

\subsubsection{Motor Power}

It is determined by the expression:

$$
\frac{P}{P_{M}}=\eta_{\text {global }}
$$

From (7) we derive $P_{M}$ :

$$
P_{M}=\frac{P}{\eta_{\text {global }}}
$$

with $P$ the useful power of the machine, $P_{M}$ the driving power and $\eta_{\text {global }}$ the overall efficiency.

\subsubsection{Motor Rotation Speed}

It is a function of the rotational speed of the Maltese cross shaft.

$$
N_{M}=\frac{N}{\eta_{\text {global }}}
$$


where $N$ is the rotational speed of the Maltese cross, $N_{M}$ is the motor speed, and $\eta_{\text {global }}$ is the overall efficiency.

\subsection{Drive Shafts}

They are essential for the operation of the drive system. The parameters of the drive train are the power, speed and torque exerted on each shaft. Thus:

$$
C=\frac{30 \times P}{\pi \times N}
$$

\subsection{Sizing of the Drive Belts}

The transmission of motion from the motor to the other components will be via V-belts. A belt is characterized by its cross section, pitch length, center distance, winding angle and maximum power rating.

\subsubsection{Selection of the Belt Cross-section}

The selection of the belt section depends on the operating power $P_{S}$ and the speed of the small driving pulley. The expression for the operating power is:

$$
P_{S}=K_{S} \times P_{M}
$$

With $K_{s}$ representing the service factor, which depends on the type of components, motor and receiver and the daily operating time, and $P_{M}$ is the motor power. Knowing the values of $P_{M}$ and $N_{M}$, we refer to the graph of transmissible power ranges by belt type to select the type of belt [13].

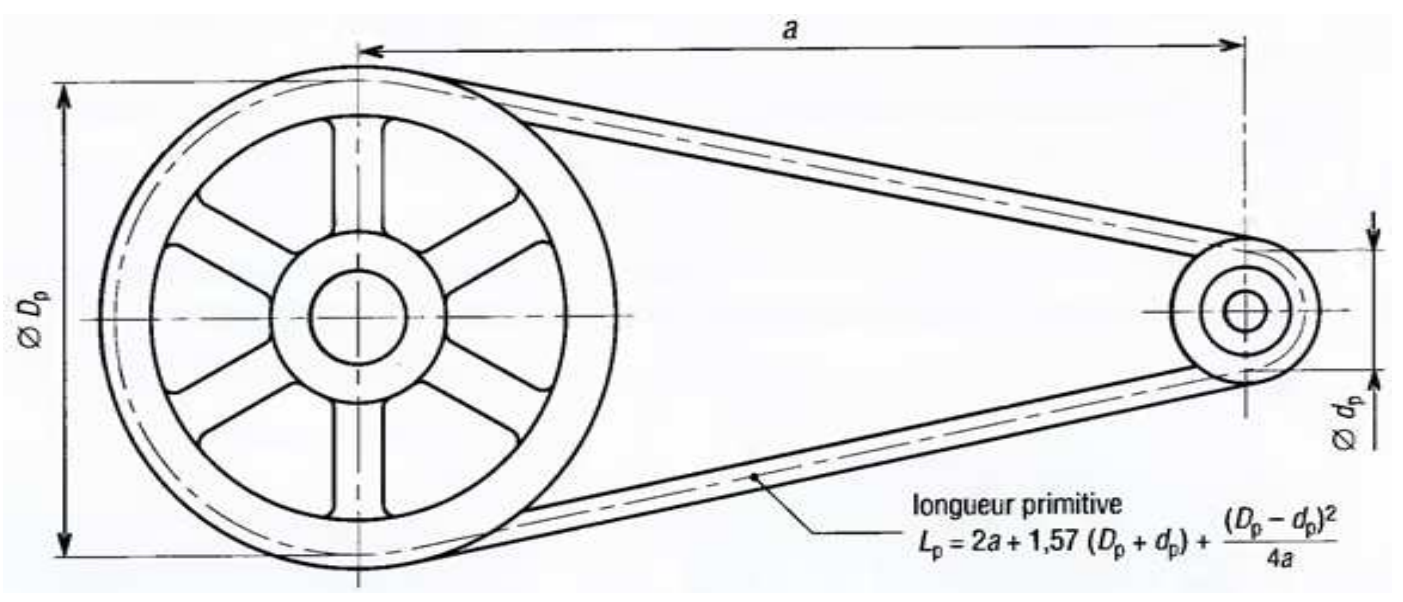

Figure 3. Primitive line of a V-belt [12].

\subsubsection{Calculation of the Belt Center Distance}

The center distance of the belts is the distance between the axes of the two pulleys. In order to determine the theoretical center distance $a$, its minimum value $\left(a_{\min }\right)$ and maximum value $\left(a_{\max }\right)$ must first be determined.

When the ratio $D^{\prime} / D$ is between 1 and 3 (as in the present case), a_min and a_max are determined by the relations (12) and (13).

With $D^{\prime}$ and $D$ meaning the pitch diameters of the large and small pulley, respectively [14]:

$$
\begin{aligned}
& a_{\text {min }}=\frac{D^{\prime}+D}{2}+D \\
& a_{\text {max }}=3\left(D+D^{\prime}\right)
\end{aligned}
$$

After determining $a_{\text {min }}$ and $a_{\text {max }}$, an approximate value for the theoretical center distance is chosen such that $a_{\text {min }} \leq$ $a<a_{\max }$.

Since the axes of the pulleys are parallel and the belt is not crossed, the theoretical length $L_{t h}$ of the belt is written [12]:

$$
L_{t h}=2 a_{t h}+1,57\left(D+D^{\prime}\right)+\frac{\left(D^{\prime}-D\right)}{a_{t h}} \times \frac{\left(D^{\prime}-D\right)}{4}
$$

After the calculation of $L_{t h}$, the table with indicative pitch lengths of V-belts is used to select a standard length which is an approximation of the calculated theoretical length.
From the standard length, the actual center distance is then calculated as follows:

$$
a=a_{t h}+\frac{L-L_{t h}}{2}
$$

\subsubsection{Calculation of the Basic Power $P_{o}$}

The basic power $P_{o}$ is a function of the linear speed $V$ and the pitch diameter $D$ of the small pulley. $V$ is expressed by:

$$
V=\pi D N_{M}
$$

Based on the table showing the basic power $P_{o}$ (in $\mathrm{kW}$ ) of conventional V-belts, $P_{o}$ is selected taking into account the calculated $V$ and $D$ [12].

\subsubsection{Calculation of the Winding Angle $\theta$}

The wrap angle is the angular deviation between the direction of the web and the horizontal. It is determined by the following formula:

$$
\theta=180^{\circ}-2 \arcsin \frac{D^{\prime}-D}{2}
$$

\subsubsection{Calculation of the Admissible Power $P_{a}$}

The admissible power $P_{a}$ is determined as follows [12]:

$$
P_{a}=P_{o} \times K_{\theta} \times K_{L}
$$

With $K_{\theta}$ the correction coefficient as a function of the 
winding angle $\theta$ and $K_{L}$ the correction coefficient as a function of the length $L$.

\subsubsection{Calculation of the Number of Belts $n$}

The number is determined by the quotient of the operating power and the permissible power.

$$
n=\frac{P_{s}}{P_{a}}
$$

\subsection{Pulleys}

The system to be designed consists of two pulleys of different diameters. The parameters considered for the pulleys are the weight and the forces that the pulleys exert on the belts.

\subsubsection{Weight of the Pulleys}

The pulleys are made of aluminum alloys. Let be, $\rho=2,7 \mathrm{~kg} / \mathrm{dm}^{3}$ the density of the pulleys and $P_{p}$ the weight of the pulley. Assume that the pulleys are cylindrical without cells of diameter $D_{p}$ and height equal to the thickness $e_{p}$ of the pulley. The weight can be determined by the formula [15]:

$$
P_{p}=\frac{\pi \times D_{p} \times D_{p} \times e_{p}}{4} \times \rho \times g
$$

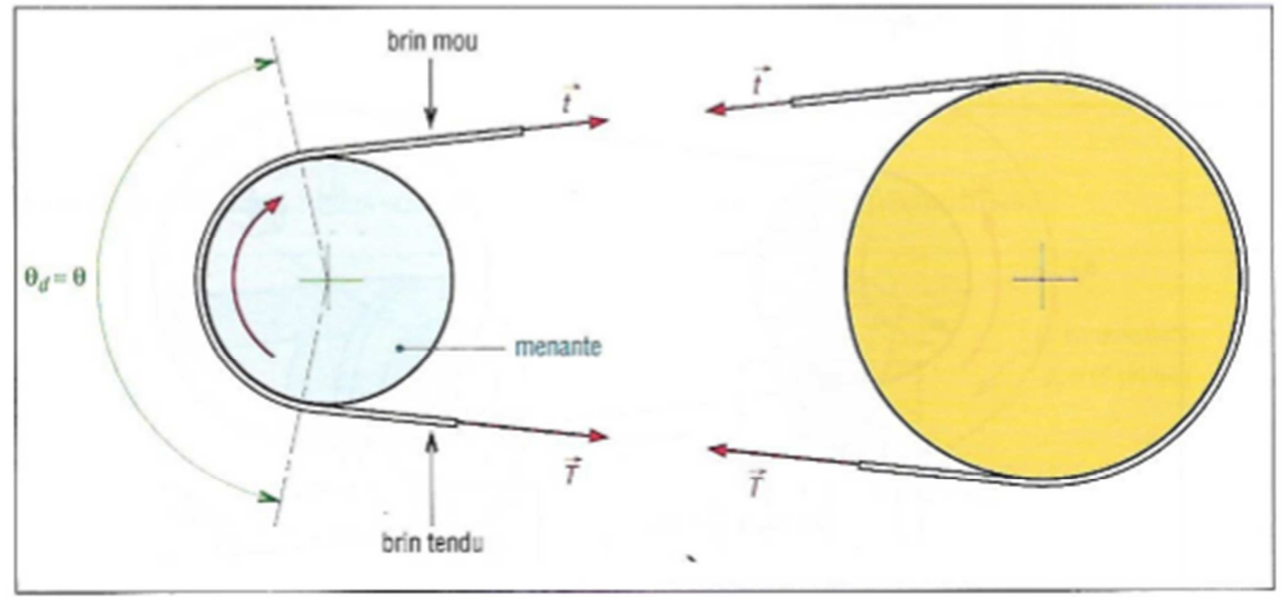

Figure 4. Tension forces [12].

\subsubsection{Operating Tension Forces of the Belts}

The belt that connects the two pulleys admits a taut strand and a slack strand. Let $T$ be the tension in the taut strand and $t$ the tension in the slack strand. $T$ and $t$ are subject to the following relationships [14]:

$$
\begin{aligned}
T-t & =\frac{2 \times C_{M}}{D} \\
\frac{T}{t} & =e^{f \theta}
\end{aligned}
$$

From these two voltages, we obtain the installation voltage

$$
T_{o}=\frac{1}{2}(T+t)
$$

The forces exerting the torque $F_{p y}$ along the horizontal and $F_{p z}$ along the vertical are then determined such that [17]:

$$
\begin{aligned}
F_{p y} & =2 n T_{o} \sin \beta \\
F_{p z} & =2 n T_{o} \cos \beta \\
\text { with } \beta & =\arcsin \frac{R^{\prime}-R}{a}
\end{aligned}
$$

$R^{\prime}$ and $R$ being respectively the radii of the driven pulley and the driving pulley and a the actual center distance.

\subsubsection{Shaft Diameter}

During normal operation, the shafts of the dosing machine are subjected to bending, twisting and shearing. They must therefore simultaneously comply with the strength requirements. [16].

Bending strength

$$
\begin{gathered}
\tau_{t} \leq R_{p g} \\
d \geq \sqrt[3]{\frac{32 M}{\pi \sigma_{a d m}}}
\end{gathered}
$$

Shear strength

$$
\begin{gathered}
\sigma_{f} \leq R_{p} \\
d \geq \sqrt{\frac{4 T_{\max }}{\pi R_{p g}}}
\end{gathered}
$$

Resistance to torsion

$$
\begin{gathered}
\tau_{c} \leq R_{p g} \\
d \geq \sqrt[3]{\frac{16 C}{\pi R_{p g}}}
\end{gathered}
$$

With $M$ the maximum bending moment, $T_{\max }$ the maximum shear force, $C$ the maximum torque on the shaft and $R_{p g}$ the practical slip resistance of the steel used for the shaft.

After calculating the diameter in all three cases, the standard diameter immediately above the value of the largest 
of the three is selected.

\subsubsection{Estimation of the Cost of the Dosing Machine}

The global cost $(\mathrm{Cg})$ of the machine will be evaluated according to the cost $(\mathrm{Cm})$ of the materials used and the cost $(\mathrm{Cu})$ of machining the parts.

That is to say:

$$
\mathrm{Cg}=\mathrm{Cm}+\mathrm{Cu}
$$

\section{Results and Analysis}

\subsection{Results}

The results of the application of the mathematical models of the dimensioning of the components of the dosing machine are recorded in Tables 1, 2, 3, 4, 5, 6, 7, 8, 9 and the estimated overall cost of the dosing machine in Table 10 .

Table 1. Values of the characteristic parameters of the Maltese cross mechanism.

\begin{tabular}{|c|c|c|c|c|c|}
\hline Components & Parameters & & & & \\
\hline Maltese Cross & $\begin{array}{l}\text { Radius R (mm) } \\
75\end{array}$ & $\begin{array}{l}\text { Center distance } \mathrm{E}(\mathrm{mm}) \\
86\end{array}$ & $\begin{array}{l}\text { Angular speed } \omega_{0}(\mathrm{rad} / \mathrm{s}) \\
6,77\end{array}$ & $\begin{array}{l}\text { Angular acceleration } \propto_{0}\left(\mathrm{rad} / \mathrm{s}^{2}\right) \\
0,63\end{array}$ & $\begin{array}{l}\text { Power P (W) } \\
20\end{array}$ \\
\hline Crankpin & $\begin{array}{l}\text { Radius R (mm) } \\
43\end{array}$ & $\begin{array}{l}\text { Center distance } \mathrm{E}(\mathrm{mm}) \\
86\end{array}$ & $\begin{array}{l}\text { Rotation speed N (rpm) } \\
10\end{array}$ & & $\begin{array}{l}\text { Power P (W) } \\
20\end{array}$ \\
\hline
\end{tabular}

Table 2. Values of the characteristic parameters of the drive chain.

\begin{tabular}{llll}
\hline Components & Parameters & & \\
\hline & Efficiency & & Melts $\left(\eta_{c}\right)$ \\
Drive chain & Bearings $\left(\eta_{p}\right)$ & 0,6 & 0,96 \\
& 0,95 & & 0,013 \\
& Overall efficiency & & \\
\hline
\end{tabular}

Table 3. Values of the motor characteristic parameters.

\begin{tabular}{lll}
\hline Components & Parameters & \\
\hline \multirow{2}{*}{ Motor } & Power $P_{M}(\mathrm{~W})$ & Rotation speed $N_{M}(\mathrm{rpm})$ \\
& 40 & 10 \\
\hline
\end{tabular}

Table 4. Values of the characteristic parameters of the trees.

\begin{tabular}{llll}
\hline \multirow{2}{*}{ Components } & Parameters & & Rotation speed $(\boldsymbol{r p m})$ \\
\cline { 2 - 4 } & Power $(\boldsymbol{W})$ & 10 & 38,2 \\
\hline Shaft I & 40 & 10 & 38,2 \\
Shaft II & 40 & 10 & 41,06 \\
Shaft III & 43 & 250 & 1,72 \\
Shaft IV & 45 & Torque $(\boldsymbol{m})$ & \\
\hline
\end{tabular}

Table 5. Values of the characteristic parameters of the pulleys.

\begin{tabular}{llll}
\hline Components & Parameters & \\
\hline \multirow{2}{*}{ Pulleys } & Driving pulley & Driven pulley & Forces exerting the torque \\
& $P=1,51 N$ & $P_{p}=12,42 N$ & $F_{p y}=7,63 N$ \\
\hline
\end{tabular}

Table 6. Values of the characteristic parameters of the drive belt.

\begin{tabular}{llll}
\hline Components & Parameters & & \\
\hline & Operating power $\boldsymbol{P}_{\boldsymbol{s}}(\mathbf{i n} \mathbf{k W})$ & Linear speed $\boldsymbol{v}(\boldsymbol{i n} \mathbf{m} / \mathbf{s})$ & Center distance (in mm) \\
\hline \multirow{3}{*}{ Belt } & & & $a_{\text {min }}=184,5$ \\
& 0,12 & 2,47 & $\begin{array}{l}\text { Theoretical center distance }\left(\text { mm) } a_{t h}=500\right. \\
\text { Real center distance }(\operatorname{mm}) a=515,82\end{array}$ \\
\hline
\end{tabular}

Table 7. Values of the characteristic power transmission parameters of the belt.

\begin{tabular}{lllll}
\hline Components & Parameters & & & \\
\hline & Standard length $\mathbf{L}(\mathbf{m m})$ & Belt wrap angle $\boldsymbol{\theta}$ & Basic power $\boldsymbol{P}_{\boldsymbol{o}}($ in $\mathbf{k W})$ & Admissible power $\boldsymbol{P}_{\boldsymbol{a}}($ in $\mathbf{k W})$ \\
\hline Belt & 1420 & $174,44^{\circ}$ & 0,62 & 0,60 \\
\hline
\end{tabular}

Table 8. Values of the characteristic parameters of the drive shafts.

\begin{tabular}{lllll}
\hline \multirow{3}{*}{ Components } & Parameters & & \\
\cline { 2 - 4 } & $\begin{array}{l}\text { Maximal torque } \\
\boldsymbol{C}(\boldsymbol{i} \boldsymbol{N} \boldsymbol{N} \boldsymbol{m})\end{array}$ & $\begin{array}{l}\text { Maximal shear } \\
\text { force } \boldsymbol{T}_{\boldsymbol{m a x}}(\boldsymbol{i n} \boldsymbol{N})\end{array}$ & $\begin{array}{l}\text { Maximal bending moment } \\
\boldsymbol{M}(\boldsymbol{i n} \boldsymbol{N} . \boldsymbol{m})\end{array}$ \\
\hline Shaft of the Maltese cross & 38,2 & 509,59 & 5,88 & $\begin{array}{l}\text { Practical slip resistance } \\
\boldsymbol{R}_{\boldsymbol{p g}}(\boldsymbol{i n} \boldsymbol{M} \boldsymbol{P a})\end{array}$ \\
Crank pin shaft & 38,2 & 1025,8 & 27,67 & 124,25 \\
\hline
\end{tabular}


Table 9. Values of the characteristic parameters of the drive shafts.

\begin{tabular}{|c|c|c|c|c|}
\hline \multirow{3}{*}{ Components } & \multicolumn{4}{|l|}{ Parameters } \\
\hline & \multicolumn{3}{|c|}{ Diameter $d$ (in mm) } & Lengh $L$ (in $\mathrm{mm}$ ) \\
\hline & Bending strength & Shear strength & Resistance to torsion & \\
\hline $\begin{array}{l}\text { Shaft of the Maltese } \\
\text { cross }\end{array}$ & $\geq 6,96$ & $\begin{array}{l}\geq 2,28 \\
\text { Selected diameter (in mm) } 25\end{array}$ & $\geq 1,16$ & 120 \\
\hline Crank pin shaft & $\geq 11,67$ & $\begin{array}{l}\geq 3,24 \\
\text { Selected diameter (in } \mathrm{mm} \text { ) } 15\end{array}$ & $\geq 1,16$ & 135 \\
\hline
\end{tabular}

Table 10. Cost of the dosing machine.

\begin{tabular}{llll}
\hline Cost of materials (in \$) & Turning labour (in \$) & Welding labour (in \$) & Total cost (in \$) \\
\hline 796 & 22 & 54 & 872 \\
\hline
\end{tabular}

\subsection{Analysis of the Results}

\subsubsection{The Motor}

The desired characteristics for the motor of the dosing machine are the following: $P_{M}=0.04 \mathrm{~kW}$ and regime $N_{M}=$ $10 \mathrm{rpm}$. For safety reasons (risk of overloading) and because the values found are not within the standard range of motor characteristics, the motor with the next highest power rating is selected. After consulting the catalog of electric motors, the LP 90L electric motor of power $P_{M}=0.09 \mathrm{KW}$ and regime $N_{M}=750 \mathrm{rpm}$ has been selected.

\subsubsection{Shaft of the Maltese Cross}

To facilitate the assembly of the cross and the plate, the diameter $d=25 \mathrm{~mm}$ is chosen.

\subsubsection{Crankpin Shaft}

The dimensioned diameter of our shaft must be greater than or equal to $11.67 \mathrm{~mm}$, a standardized diameter $d=15 \mathrm{~m} \mathrm{~m}$ has been selected, according to the Industrial Designer's Guide.

\subsubsection{Permissible Belt Power}

According to the table showing the basic power $\mathrm{Pb}$ in $\mathrm{kW}$ of conventional $\mathrm{V}$-belts, the diameter of the selected small pulley is not directly adapted to a basic power. The basic power corresponding to the diameter of the small pulley was first determined by an interpolation method. Then by the same method, the basic power corresponding to the linear speed of the belt was determined.

\subsubsection{Total cost of the Machine}

The cost of the equipment was evaluated at 872 \$. Given the still relatively low selling power of locally produced tomato paste, few processors could afford to buy it. The government should support these processors with subsidies.

\section{Conclusion}

The present study aims at the development of the tomato sector in Benin by the development of a dosing machine allowing to reduce the laboriousness of the tomato transformation process. It allowed the design and estimation of the tomato paste dosing machine. This equipment has a good working precision and is ergonomic. Its manufacture will not cause any difficulties in a mechanical workshop with adequate machine tools. The evaluation of its cost implies the accessibility to any processor of the tomato although the sector is not until now on an industrial scale. However the realization of a model and tests in size and nature will allow to evaluate the technical-economic performances of the dosing machine of tomato puree and to improve them by the same occasion. Indeed, the manufacture of this equipment should have considerable socio-economic benefits for the agricultural sector which is underdeveloped.

\section{References}

[1] YEHOUESSI L. W., (2012). Study of the agronomic performance of the off-season tomato crop in the coastal zone of southern Benin (Cotonou - Pahou - Grand-Popo), PhD thesis, University of Abomey-Calavi, Benin, $178 \mathrm{p}$.

[2] DSA/MAEP (2016). Statistical yearbook of agricultural production in Benin. Ministry of Agriculture, Livestock and Fisheries, $56 \mathrm{p}$.

[3] ASSOGBA K. F., Sikirou R., Azagba J., (2013). How to successfully grow tomatoes in all seasons: Case of urban and peri-urban areas of southern Benin. Institut National des Recherches Agricoles du Bénin. Référentiel technicoéconomique (RTE). Edition 2013, 58 p.

[4] BOUMENDJEL M. M., Boutebba M., (2003). Effect of sterilization scales on the biochemical and nutritional quality of canned tomatoes. Sciences et Technologies, 20, 51-55.

[5] HOUSSOU P. A., Dansou V., Ayi-Fanou L., Abdelkerim A. D., Mensah G. A., 2015. Technology for simultaneous production of tomato puree and juice. International Journal of Biological and Chemical Science, 9 (5), 24682476.

[6] DOSSOU J., Soulé I., Montcho M. (2007). Evaluation of physicochemical and sensory characteristics of local tomato puree produced on a small scale in Benin. Tropicultura, 25, 119-125.

[7] MONTCHO M. D., (2002). Processing of local tomato into puree: a solution approach to reduce production losses during market saturation. In Rural Universe NetworkSPIPM Interactive article \#1064, 262270.

[8] FAGBOHOUN O., Kiki D., (1999). Overview of the main local tomato varieties grown in southern Benin. Agronomic Research Bulletin, 24, 10-21.

[9] MENSAH A. (2004). Evaluation of the technical performance of the tomato cultivation system in the communes of Ouidah and Grand-Popo in southern Benin; Dissertation for the degree of engineer, University of Lomé, Togo, $80 \mathrm{p}$. 
[10] https://fr.wikipedia.org/w/index.php? title=croix de malte mechanism $=174764642$

[11] YEMADJE Francis, (2016), Study and design of a pineapple peeler-cutter, Thesis for obtaining a higher technician, University of Abomey-Calavi.

[12] ABDOU Kêfil, (2020), Study and realization of a pineapple peeler-cutter. Thesis for obtaining a higher technician, National University of Agriculture.

[13] FANCHON J-L., (2001) Science and technology guide, NATHAN, $592 \mathrm{p}$.
[14] Francis Esnault, David Coquard (2017) Mechanical Engineering Power Transmission Volume 1. Basics of Construction and Ecodesign. 4th EDITION.

[15] FANOU André, (2018) Study, design and realization of a banana trunk defibrillator, Thesis for obtaining a higher technician, University of Abomey-Calavi.

[16] Dr. Abdoulaye ASSOUDO, (2019) Resistance of materials course II, University of Abomey-calavi, Polytechnic School of Abomey-calavi, department of mechanical engineering and energetics. 